\title{
A Review on Strongyloidiasis in Pregnant Women
}

\author{
Philip Wikman- \\ Jorgensen (D) \\ Ana Requena-Méndez ${ }^{2,3}$ \\ Jara Llenas-García (iD) 4,5 \\ 'Internal Medicine Department, Hospital \\ Universitario San Juan de Alicante- \\ FISABIO, San Juan de Alicante, Alicante, \\ Spain; ${ }^{2}$ Barcelona Institute for Global \\ Health (ISGlobal, Hospital Clinic- \\ Universitat de Barcelona), Barcelona, \\ Spain; ${ }^{3}$ Department of Medicine Solna, \\ Karolinska Institutet, Stockholm, Sweden; \\ ${ }^{4}$ Internal Medicine and Infectious \\ Diseases Department, Hospital Vega \\ Baja-FISABIO, Alicante, Spain; ${ }^{5}$ Clinical \\ Medicine Department, Universidad \\ Miguel Hernández de Elche, Elche, Spain
}

Correspondence: Philip WikmanJorgensen

Hospital Universitario San Juan de Alicante-FISABIO, Internal Medicine Department, Ctra N-332 s/n, San Juan de Alicante, Alicante, Spain

Email wikman_phi@gva.es

\begin{abstract}
Strongyloidiasis is a parasitic infection distributed worldwide, with an estimated 614 million people infected. Strongyloidiasis usually presents asymptomatically or with aspecific and mild clinical symptoms, mainly cutaneous, respiratory, or gastrointestinal. Disseminated disease and hyperinfection syndrome are the most serious complications, have a high mortality rate, usually occur in immunosuppressed patients, and are particularly associated with the use of corticosteroids. Strongyloidiasis is the most neglected of the neglected diseases, and its occurrence in pregnancy has been neglected and understudied. In this review, we focus on the effects of strongyloidiasis during pregnancy and highlight the knowledge shortage and the need for more research on the subject. There are few studies addressing strongyloidiasis prevalence during pregnancy and hyperinfection incidence during pregnancy is practically unknown, with only isolated case reports published. Although data are scarce, the infection has been associated with developmental disabilities and anemia during pregnancy, while hyperinfection may cause both maternal and neonatal death. Data on the best screening and diagnostic strategies during pregnancy are lacking. There is insufficient evidence on ivermectin safety in pregnancy, complicating treatment recommendations.
\end{abstract}

Keywords: strongyloides, pregnancy, hyperinfection, anemia, stillbirth

\section{Background}

Strongyloides stercoralisis an intestinal helminth that causes a parasitic infection in humans called strongyloidiasis. This nematode has a worldwide distribution, but it is more frequent in tropical and subtropical areas. However, it may also be present in mild countries with favorable conditions. ${ }^{1}$ Within these regions, exposure to infection is strongly associated with poor sanitary and living conditions, and thus certain vulnerable populations (such as refugees or occupationally soil-exposed groups) are at especially high risk of strongyloidiasis. Strongyloidiasis is thus primarily determined by the socioeconomic status of communities, rather than geographic or climatic conditions, and should no longer be referred to as a "tropical" disease, but rather a disease of disadvantage. ${ }^{2}$

It is estimated that at least 613.9 (95\% CI 313.1-910.1) million people are infected worldwide. ${ }^{3,4}$ A recent systematic review estimated a pooled seroprevalence of $12.2 \%(95 \%$ CI $9 \%-15.9 \%)$ in migrants from endemic areas residing in nonendemic areas, ${ }^{5}$ while a similar study in Spain yielded a Strongyloides seroprevalence of $14 \%$ among migrants from endemic areas. ${ }^{6}$

Strongyloidiasis usually presents asymptomatically or with aspecific and mild clinical symptoms related to skin penetration (rash, urticaria, larva currens), migration through the body (cough, sore throat, pulmonary infiltrates), and presence of the adult helminth in the intestine (abdominal pain, diarrhea, nausea, or vomiting, among others). ${ }^{1}$ Disseminated disease and hyperinfection syndrome are the most serious 
complications of the infection, and they mostly occur in immunosuppressed patients and are particularly associated with the use of corticosteroids. ${ }^{7}$ However, many other conditions causing immunosuppression (such as leukemia or transplant, immunosuppressive agents, hypogammaglobulinemia, malnutrition) have also been associated with a severe form of the disease, with a reported mortality up to $62 \%$ in the case of disseminated disease. ${ }^{8}$ Other less immunosuppressant states, such as alcoholism and liver cirrhosis, have also been associated with disseminated disease. ${ }^{9}$ Severe cases have also been reported in pregnant women, another condition with altered immunostatus. ${ }^{10}$ There are many knowns and unknowns (Table 1) regarding S. stercoralis infection during pregnancy.

Diagnosis of strongyloidiasis has improved thanks to enhanced microscopy-based direct techniques, such as agar-plate culture or the Baermann method, but their

Table I Summary of knowns and unknowns regarding Strongyloides stercoralis infection during pregnancy

\begin{tabular}{|c|c|c|}
\hline & What is known & What is unknown \\
\hline Prevalence & $\begin{array}{l}\text { Few studies exist. Seems } \\
\text { to mirror that of the } \\
\text { general population. } \\
\text { Higher in rural areas. }\end{array}$ & $\begin{array}{l}\text { Very little data to draw } \\
\text { firm and solid } \\
\text { conclusions. }\end{array}$ \\
\hline $\begin{array}{l}\text { Diagnostic } \\
\text { methods }\end{array}$ & $\begin{array}{l}\text { Most frequent is single } \\
\text { stool evaluation with } \\
\text { a concentration method. }\end{array}$ & $\begin{array}{l}\text { Sensitivity and specificity } \\
\text { of serology, } \\
\text { which is the optimal } \\
\text { diagnostic technique. } \\
\text { Need for combination } \\
\text { techniques. }\end{array}$ \\
\hline $\begin{array}{l}\text { Effect on } \\
\text { the } \\
\text { mother }\end{array}$ & $\begin{array}{c}\text { Cases of severe } \\
\text { strongyloidiasis have been } \\
\text { described. }\end{array}$ & $\begin{array}{l}\text { Risk of the pregnancy } \\
\text { per se as a trigger of } \\
\text { hyperinfection is } \\
\text { unknown. }\end{array}$ \\
\hline $\begin{array}{l}\text { Effect on } \\
\text { the fetus }\end{array}$ & $\begin{array}{l}\text { Developmental issues } \\
\text { have been described, as } \\
\text { well as low birth weight. }\end{array}$ & $\begin{array}{l}\text { Causality has not been } \\
\text { established, only } \\
\text { association. }\end{array}$ \\
\hline Treatment & $\begin{array}{l}\text { Ivermectin is the } \\
\text { treatment of choice } \\
\text { outside pregnancy and } \\
\text { should be offered to } \\
\text { pregnant women with } \\
\text { severe presentations. }\end{array}$ & $\begin{array}{l}\text { There is not much safety } \\
\text { data on the use of } \\
\text { ivermectin during } \\
\text { pregnancy. Benefit:risk } \\
\text { ratio for treating } \\
\text { nonsevere cases in } \\
\text { pregnant women not at } \\
\text { risk of } \\
\text { immunosuppression } \\
\text { needed. }\end{array}$ \\
\hline
\end{tabular}

sensitivity remains low due to the intermittent larval excretion and a low parasitic burden. ${ }^{7}$ Due to its accuracy, simplicity, and reproducibility, serology is today the most widespread technique used. ${ }^{7}$ However, serological tests may be less specific in endemic regions, due to cross reactivity with other helminthic diseases, although increasing the serology cutoff may overcome this issue. ${ }^{11}$ Sensitivity and specificity in pregnant women is unclear.

In terms of treatment, ivermectin is currently the drug of choice. $^{12}$ The optimal dosage schedule for ivermectin has recently been demonstrated to be one dose for uncomplicated chronic strongyloidiasis. ${ }^{13}$ A recent systematic review and meta-analysis has however raised concern about the scarcity of safety data on ivermectin in pregnant women. ${ }^{14}$

During pregnancy, a certain immunosuppression has been postulated, although it remains unclear how this affects clinical aspects and evolution of the infection and how S. stercoralis affects the immune system of the mother and the fetus.

In this review, we focus on the effects of strongyloidiasis during pregnancy and highlight the knowledge shortage and the need for more research on the subject.

\section{Prevalence of Infection in Pregnant Women}

There have been few studies to address the prevalence of Strongyloides spp. infection in pregnant women. In one study conducted in rural Peru, the estimated prevalence ranged from $10 \%$ with stool-based techniques to $33 \%$ with serological methods. ${ }^{15}$ In other studies from Venezuela and Kenya, prevalence was $0-9.2 \%$, but only stool-based diagnostic methods were used. ${ }^{16,17}$ A recent systematic review found a mean prevalence of $12.3 \%$, with a median of $6 \%$ and higher prevalence in rural areas. ${ }^{18}$ Regional variation, pregnancy trimester, and diagnostic methods used may explain most of this variability. Also, the Venezuelan study excluded malnourished pregnant women. Most studies use spot feces sampling and direct microscopy evaluation after a concentration method has been performed. However, when Strongyloides charcoal culture is performed, the prevalence seems to be higher. ${ }^{15,19}$ In an Australian study, there were implementation issues leading to only 60 of 86 women being screened by serology, and seroprevalence of $3.3 \%$ was reported. $^{20}$

\section{Diagnosis of Strongyloidiasis in Pregnant Women}

Serology has been proposed as a possibly useful tool for the screening of strongyloidiasis in pregnancy, but there are some caveats. Diagnostic accuracy in immunosuppressed 
patients is not clear and seems to be lower. ${ }^{21}$ In this subgroup, a combination of techniques has been recommended. ${ }^{22}$

In pregnant women who have little immunosuppression, serology accuracy has not been well studied. To the best of our knowledge, there has been only one study to evaluate the sensitivity and specificity of serology in pregnant women. Ortiz-Martínez et al evaluated the prevalence of Strongyloides infection among pregnant women using different techniques. ${ }^{15}$ They found serology to have sensitivity of $61.3 \%$ and specificity of $69.6 \%$, clearly below the general population, ${ }^{7}$ raising concern as to its applicability in pregnant women. However, the choice of gold standard is questionable, and the optical density cutoff chosen for serology positivity was not reported. Also, the study did not provide data to estimate sensitivity in the general population, which prevents drawing conclusions on the accuracy of serology in pregnant women. In addition, serology is the gold standard for detecting many other parasitic infections (eg, Chagas diseases or toxoplasmosis, among others) without concerns about potentially decreased sensitivity of the techniques. ${ }^{23,24}$

Information on the accuracy of Strongyloides diagnostic tools in pregnancy is very scarce. A well-designed comparative study of different strongyloidiasis diagnostic techniques in pregnant women is much needed.

\section{Immunopathophysiology of Strongyloides Infection and Pregnancy}

Chronic strongyloidiasis has been associated with $T_{h} 2$ immunoresponse. $\mathrm{CD}^{+} \mathrm{T}$ cells can differentiate mainly into two different T-helper cell types: $T_{h} 1$ and $T h 2 . T_{h} 1$ cells activate a cytotoxic response through cytokines (IFN $\gamma, \mathrm{TNF} \alpha$, IL12). $\mathrm{T}_{\mathrm{h}} 2$ cells activate the humoral immunoresponse system and the secretion of IL4 and IL5. IL4 ultimately stimulates IgE production, and IL5 signals eosinophils. Therefore, Strongyloides infection is capable of downregulating host immunity, protecting them from being eliminated and also minimizing severe pathology in the host. However, the immunological mechanisms manifesting in severe forms of the infection in immunosuppressed patients, particularly those on steroids, are poorly understood. ${ }^{25}$ During pregnancy, the classical view is that the $T_{h} 1$ response is downregulated, whereas the $\mathrm{T}_{\mathrm{h}} 2$ response predominates, as it occurs in chronic infection. However, several studies have challenged this view as overly simplistic, and immunology of pregnancy is viewed more as a result of a complex interplay of signals between the maternal immune system and the fetal-placental immune system. ${ }^{26}$ In general, the T-helper response is diminished during pregnancy, as well as other elements of the adaptive immunoresponse. On the other hand, there is evidence on the exacerbation of the innate immunoresponse of natural killer cells, monocytes, and plasmacytoid dendritic cells. ${ }^{27,28}$ Immunological changes are dynamic over time during pregnancy, with three different phases. During the first trimester, the implantation and placentation resemble an "open wound" and there is a need for a strong inflammatory response. ${ }^{29}$ The blastocyst must break through several structures in order to implant, so an inflammatory environment is required to secure adequate repair of the uterine epithelium and the removal of cellular debris. Therefore, the first trimester is a proinflammatory phase. In the second trimester of pregnancy, an anti-inflammatory state is more predominant, and during the third trimester, a new inflammatory process is needed to induce labor. This chronological evolution of immunology during pregnancy was captured recently in a model defining the immunological clockwork of the immune system during pregnancy. ${ }^{30}$ Therefore, as there are different periods, it could be expected that the larval burden may vary throughout the pregnancy, as well as symptoms, risk of hyperinfection, and the possibility of detecting larvae in feces.

S. stercoralis is a helminth that is canonically controlled by a $\mathrm{T}_{\mathrm{h}} 2$ immunological response. Nevertheless, eradication of migrating $\mathrm{L}_{3}$ larvae is mediated predominantly not only by eosinophils but also by neutrophils. ${ }^{31}$ Efficient expulsion of the helminth from the intestine is mediated by basophils and mast cells. This is an innate response triggered by IL33 and dependent on ILC2, IL9, and mast cells. ${ }^{32}$ Patients infected with Strongyloides spp. show little intestinal inflammation, suggesting that Strongyloides does not activate the IL33 pathway in humans intensely. However, there is a marked reduction in the number of dividing macrophages and replicating enterocytes compared with controls. ${ }^{33}$

\section{Obstetric Complications}

Pregnant women are especially susceptible to certain parasitic infections, such as malaria. Being pregnant is a risk factor of severe malaria, and associations with maternal anemia, stillbirth, and low birth weight (LBW) are well established. ${ }^{34}$ Evidence from other helminth infections suggest that they are also associated with obstetric complications like stillbirth, abortion, intrauterine growth 
retardation, and LBW. ${ }^{35}$ The underlying mechanisms of these associations is unclear, as so far treatment of helminths during pregnancy has not shown benefits in terms of fetal outcomes. ${ }^{36}$ Therefore, it is possible that the associations found are more a reflection of underlying social conditions than a direct effect of helminths. Nevertheless, data on the specific effects of strongyloidiasis are even more scarce. There have been case reports of stillbirth due to Strongyloides hyperinfection in pregnant women. ${ }^{10}$ However, beyond those cases reported, the impact of Strongyloides on stillbirth is unclear. Other studies have found that strongyloidiasis increases the odds of LBW. A study from Tanzania found an association of strongyloidiasis with 5.97 (95\% CI 1.23-28.98) times the adjusted relative odds of LBW. ${ }^{37}$ Another study from Thailand found an OR of 2.59 (95\% CI 1.09-6.16), and ${ }^{38}$ a study from Ghana found an OR of 2.1 (95\% CI $0.97-4.49$, $p=0.05$ ) for LBW, small for gestational age, or preterm delivery. ${ }^{39}$ However, all these were cross-sectional studies, and despite adjusting for confounders, causality could not be demonstrated. Evidence from other helminth infections suggests this possible association as well, pointing out that the most important factor to correct is the mother's anemia. ${ }^{40}$ However, of five studies that searched for an association between Strongyloides and maternal anemia, only one found helminth infections to be a predictor of maternal anemia, but helminths were considered as a whole and no differential effect of Strongyloides could be found. ${ }^{18}$

\section{Developmental Complications}

Some reports have addressed the long-term impact on height and weight of Strongyloides infection in children, ${ }^{18,41}$ showing decreased, although not always statistically significant, weight for height or weight for age $Z$-scores. However, from these reports it can be interpreted that malnutrition is a driving force behind the findings, but it cannot be concluded whether Strongyloides drives malnutrition or malnutrition facilitates Strongyloides infestation.

One study found that helminth infection during pregnancy was associated with poor cognitive and gross motor functions at 12 months of age, even after adjusting for gravidity, maternal education, family possession, child sex, and HOME score. ${ }^{42}$ In this study, Strongyloides was found among the intestinal helminths assessed, but was not the only one.

\section{Risk of Disseminated Disease}

Few case reports have been found in the medical literature on Strongyloides hyperinfection in pregnancy. ${ }^{10,43-45}$ In two of the cases reported, both the mother and the fetus died. In the other two, both recovered successfully. Three cases were migrants from endemic areas living in highincome countries. However, there is no hard evidence on the increased risk of severe strongyloidiasis during pregnancy, as there have not been prospective studies on maternal and fetal outcomes of infected pregnant women. Nonetheless, pregnant women may well be affected by severe strongyloidiasis through two mechanisms: pregnancy-induced immunosuppression and chronic nutritional deficiencies. It could well be that severe hyperinfection cases in pregnancy are occurring inadvertently in poor rural areas, where maternal deaths are not systematically studied. Moreover, drugs used during pregnancy like corticosteroids for preterm labour could potentially trigger a severe outcome. ${ }^{10,44}$ Therefore, it is advisable to proceed with caution when prescribing steroids in populations with high endemicity of strongyloidiasis or migrants from these areas. A recent study suggested that presumptive treatment is cost-effective in migrants from endemic areas at risk of being immunosuppressed. ${ }^{46}$ In our opinion, in pregnant women coming from endemic areas, current uncertainty about ivermectin safety in pregnancy precludes the use of widespread presumptive treatment. However, what would be desirable is to screen childbearing-age women for strongyloidiasis and treat them before pregnancy.

\section{Treatment of Strongyloidiasis During Pregnancy}

The drug of choice for the treatment of strongyloidiasis is ivermectin. ${ }^{12}$ The optimal dosage schedule of ivermectin has recently been demonstrated to be one dose for uncomplicated chronic strongyloidiasis. ${ }^{13}$

A recent systematic review and meta-analysis has raised concern about the scarcity of safety data for ivermectin in pregnant women, ${ }^{14}$ highlighting an important knowledge gap in this subgroup of patients. The few data available and analyzed did not point toward any obvious adverse effects; however, the low number of cases analyzed and the low quality of the evidence does not allow a firm conclusion on safety. ${ }^{14}$ An open data repository of inadvertent ivermectin drug exposure during pregnancy has been proposed as a strategy to mitigate this lack of 
knowledge. ${ }^{14}$ A randomized clinical trial has also been advocated for. ${ }^{47,48}$

Ivermectin is an FDA class $\mathrm{C}$ drug, meaning that:

Animal reproduction studies have shown an adverse effect on the fetus and there are no adequate and well-controlled studies in humans, but potential benefits may warrant use of the drug in pregnant women despite potential risks. ${ }^{49}$

For the treatment of severe cases of strongyloidiasis during pregnancy, we believe that benefits outweigh the risks and ivermectin should be used. In cases where immunosuppressant drugs are used, such as corticosteroids for preterm labour, and Strongyloidiasis cannot be ruled out, presumptive treatment could be an option after discussing with the woman the benefits and risks of that strategy. Screening for strongyloidiasis and treating only those pregnant women screening positive and at risk of immunosuppression could avoid unnecessary ivermectin exposure, but availability of the results in time is a limiting issue in most settings.

Treatment of nonsevere cases during pregnancy in women not receiving immunosuppressants is unclear, and the benefits and risks are difficult to evaluate, as the risk of developing hyperinfection and adverse pregnancy outcome due to ivermectin have not been appropriately established. Although fetus adverse effects in animals have been seen with doses that were toxic to the mother and 60-200 times above the human therapeutic target, ${ }^{50}$ the CDC does not recommend presumptive treatment in healthy pregnant women coming from endemic areas. ${ }^{51}$ For those confirmed cases of Strongyloides infection in pregnant women not receiving immunosuppressants, there is no clear recommendation. Other second-line regimens for the treatment of strongyloidiasis include albendazole. Despite being classified as an FDA class $\mathrm{C}$ drug (reference), it seems to have a more established safety profile (although with less efficacy), and could be considered. ${ }^{52}$ We believe that if treatment during pregnancy is to be offered to nonsevere not-at-risk women, their choice should be considered after a thorough discussion on treatment benefits and risks. Close follow-up and prompt treatment only if needed is also an approach to be considered.

Both ivermectin and albendazole should be avoided during the first trimester. Due to its lower efficacy, if albendazole is given during pregnancy, treatment with ivermectin after delivery may be considered.

\section{Discussion}

There is not much evidence on the interaction between strongyloidiasis and pregnancy. Strongyloidiasis prevalence in pregnant women seems to be similar to the general population from the area in question. However, in most studies, the most frequent diagnostic method reported was the single stool direct microscopic examination with or without a concentration procedure. This is a technique that is far from optimal, and thus the burden of strongyloidiasis in pregnant women is probably underreported and underestimated. Studies using culture techniques have yielded higher prevalence of Strongyloides infection. There are very limited data on the use of serology during pregnancy. Difficulties in compliance with testing protocols using serology have been reported..$^{20}$ There is a clear need to include reliable serological tests in further studies of Strongyloides prevalence in pregnant women. Worldwide, health-care providers would benefit from more accurate prevalence data to appropriately manage strongyloidiasis in pregnant women and women of childbearing age. We believe that prevalence and thus health effects of strongyloidiasis in pregnancy are most probably underestimated in the current literature.

Studies looking at the effects of strongyloidiasis on pregnant women and their offspring are scarce. Strongyloidiasis has been found to be associated with some adverse obstetric outcomes and infant developmental outcomes. However, the causality of these outcomes has not been established as malnutrition, and other conditions (such as HIV infection and poverty) are confounding factors. Therefore, we cannot determine whether S. stercoralis infection in the mother is an independent risk factor of LBW, small for gestational age, intrauterine growth retardation, or preterm delivery.

The most concerning adverse outcome of strongyloidiasis during pregnancy is the risk of hyperinfection. Fatal cases have been reported in the literature. Although there is no strong evidence for any treatment recommendations in pregnant women, for severe strongyloidiasis we believe the use of ivermectin outweighs the risks. For pregnant women not on immunosuppressants, close follow-up and prompt treatment if needed seems a reasonable strategy.

In pregnant women that are going to receive immunosuppressants, screening and treatment of positive cases or presumptive treatment are options to consider and discuss with the mother after a thorough evaluation of the specific risks and benefits of every individual case. 
We believe there are enough arguments to support increased screening and treatment of strongyloidiasis in pregnant women to confer the best-possible outcomes for them and their children. However, ivermectin efficacy and safety in pregnancy should be urgently evaluated through well-designed studies.

As this is a narrative review with no systematic research strategy for the literature, bias may be of concern. However, the review is very comprehensive and our conclusions are in line with other similar but systematic reports, indicating a high degree of consistency. ${ }^{18,36}$ The main limitation of this review is the scarcity of reports on different issues associated with strongyloidiasis in pregnant women. Many open questions remain, and studies are warranted to assess the optimal diagnostic method for Strongyloides infection in pregnant women, the impact of Strongyloides infection on maternal and newborn outcomes, if there are long-term effects on child growth and development, if pregnancy itself is a risk factor of the development of Strongyloides hyperinfection, and what the effectiveness and safety of ivermectin treatment in pregnant women is.

In conclusion, we strongly believe that pregnant women should be protected through research and not from research. Well-designed studies directed to evaluate all these questions regarding the interaction between Strongyloides and pregnancy are urgently needed. Furthermore, evidence-based protocols of Strongyloides screening and treatment before, during, and after pregnancy should be developed and implemented, both in developed and developing countries. We need to provide evidence-based care to the thus far neglected pregnant women with Strongyloides infection.

\section{Disclosure}

The authors report no conflicts of interest for this work.

\section{References}

1. Olsen A, van Lieshout L, Marti H, et al. Strongyloidiasis - the most neglected of the neglected tropical diseases? Trans $R$ Soc Trop Med Hyg. 2009;103(10):967-972. doi:10.1016/j.trstmh.2009.02.013

2. Beknazarova M, Whiley H, Ross K. Strongyloidiasis: a disease of socioeconomic disadvantage. Int $J$ Environ Res Public Health. 2016;13:5. doi:10.3390/ijerph13050517

3. Buonfrate D, Bisanzio D, Giorli G, et al. The global prevalence of strongyloides stercoralis infection. Pathogens. 2020;9(6):1-9. doi:10.3390/pathogens 9060468

4. Bisoffi Z, Buonfrate D, Montresor A, et al. Strongyloides stercoralis: a Plea for Action. PLoS Negl Trop Dis. 2013;7(5):7-10. doi:10.1371/ journal.pntd.0002214
5. Asundi A, Beliavsky A, Liu XJ, et al. Prevalence of strongyloidiasis and schistosomiasis among migrants: a systematic review and meta-analysis. Lancet Glob Heal. 2019;7(2):e236-e248. doi:10. 1016/S2214-109X(18)30490-X

6. Salvador F, Treviño B, Bosch-Nicolau P, et al. Strongyloidiasis screening in migrants living in Spain: systematic review and meta-analysis. Trop Med Int Heal. 2020;25(3):281-290. doi:10. $1111 /$ tmi. 13352

7. Requena-Méndez A, Chiodini P, Bisoffi Z, Buonfrate D, Gotuzzo E, Muñoz J. The laboratory diagnosis and follow up of strongyloidiasis: a systematic review. PLoS Negl Trop Dis. 2013;7:1. doi:10.1371/ journal.pntd.0002002

8. Buonfrate D, Requena-Mendez A, Angheben A, et al. Severe strongyloidiasis: a systematic review of case reports. BMC Infect Dis. 2013;13(1):1. doi:10.1186/1471-2334-13-78

9. Teixeira MCA, Pacheco FTF, Souza JN, Silva MLS, Inês EJ, Soares NM. Strongyloides stercoralis Infection in Alcoholic Patients. Biomed Res Int. 2016;2016:1-11. doi:10.1155/2016/4872473

10. Buresch AM, Judge NE, Dayal AK, Garry DJ, Fatal A. Case of Strongyloidiasis in Pregnancy. Obstet Gynecol. 2015;126(1):87-89. doi:10.1097/AOG.0000000000000676

11. Bisoffi Z, Buonfrate D, Sequi M, et al. Diagnostic accuracy of five serologic tests for strongyloides stercoralis infection. PLoS Negl Trop Dis. 2014;8(1):38. doi:10.1371/journal.pntd.0002640

12. Henriquez-Camacho C, Gotuzzo E, Echevarria J, et al. Ivermectin versus albendazole or thiabendazole for Strongyloides stercoralis infection. Cochrane Database Syst Rev. 2016;2016:1. doi:10.1002/ 14651858.CD007745.pub3

13. Buonfrate D, Salas-Coronas J, Muñoz J, et al. Multiple-dose versus single-dose ivermectin for Strongyloides stercoralis infection (Strong Treat 1 to 4): a multicentre, open-label, Phase 3, randomised controlled superiority trial. Lancet Infect Dis. 2019:23. doi:10.1016/ S1473-3099(19)30289-0

14. Nicolas P, Maia MF, Bassat Q, et al. Safety of oral ivermectin during pregnancy: a systematic review and meta-analysis. Lancet Glob Heal. 2020;8(1):e92-e100. doi:10.1016/S2214-109X(19)30453-X

15. Ortiz-Martínez S, Ramos-Rincón JM, Vásquez-Chasnamote ME, et al. A cross-sectional study of seroprevalence of strongyloidiasis in pregnant women (Peruvian Amazon basin). Pathogens. 2020;9 (5):348. doi:10.3390/pathogens 9050348

16. Acurero OE, Díaz AI, Díaz AN, Bracho MA, Ferrer HM, Matheus MA. Prevalencia de enteroparásitos en embarazadas de la maternidad "Dr. Armando Castillo Plaza" en Maracaibo Venezuela TT - Prevalence of enteroparasitism in pregnant women at the "Dr. Armando Castillo Plaza" maternity center Maracaibo Venezuela. Kasmera. 2008;36(2):148-158.

17. McClure EM, Meshnick SR, Mungai $P$, et al. The association of parasitic infections in pregnancy and maternal and fetal anemia: a cohort study in coastal Kenya. PLoS Negl Trop Dis. 2014;8(2): e2724. doi:10.1371/journal.pntd.0002724

18. Paltridge M, Traves A. The Health Effects of Strongyloidiasis on Pregnant Women and Children: a Systematic Literature Review. Trop Med Infect Dis. 2018;3(2):50. doi:10.3390/tropicalmed3020050

19. Ndibazza J, Muhangi L, Akishule D, et al. Effects of Deworming during Pregnancy on Maternal and Controlled Trial. Clin Infect Dis. 2010;50(4):531-540. doi:10.1086/649924

20. Paltridge M, Traves A, de Costa C, McDermott R. Low prevalence of strongyloidiasis in Far North Queensland pregnant women. Aust J Rural Health. 2019;27(5):438-439. doi:10.1111/ajr.12521

21. Luvira V, Trakulhun K, Mungthin M, et al. Comparative diagnosis of strongyloidiasis in immunocompromised patients. Am J Trop Med Hyg. 2016;95(2):401-404. doi:10.4269/ajtmh.16-0068

22. Requena-Méndez A, Buonfrate D, Gomez-Junyent J, Zammarchi L, Bisoffi Z, Muñoz J. Evidence-based guidelines for screening and management of strongyloidiasis in non-endemic countries. $\mathrm{Am}$ J Trop Med Hyg. 2017;97(3):645-652. doi:10.4269/ajtmh.16-0923 
23. Basile L, Ciruela P, Requena-Méndez A, et al. Epidemiology of congenital Chagas disease 6 years after implementation of a public health surveillance system, Catalonia, 2010 to 2015. Eurosurveillance. 2019;24(26). doi:10.2807/1560-7917.ES.2019.24.26.19-00011

24. Wallon M, Fricker-Hidalgo H, Chapey E, et al. Performance of a Toxo IgM prototype assay for the diagnosis of maternal and congenital Toxoplasma infections. Clin Chem Lab Med. 2020;58 (11):1959-1964. doi:10.1515/cclm-2019-1199

25. Tiberti N, Buonfrate D, Carbone C, Piro G, Bisoffi Z, Piubelli C. Systemic profile of immune factors in an elderly Italian population affected by chronic strongyloidiasis. Parasit Vectors. 2020;13 (1):1-14. doi:10.1186/s13071-020-04391-w

26. Mor G, Cardenas I, Abrahams V, Guller S. Inflammation and pregnancy: the role of the immune system at the implantation site. Ann N Y Acad Sci. 2011;1221(1):80-87. doi:10.1111/j.1749-6632.2010.05938.x

27. Kay AW, Fukuyama J, Aziz N, et al. Enhanced natural killer-cell and T-cell responses to influenza A virus during pregnancy. Proc Natl Acad Sci U S A. 2014;111(40):14506-14511. doi:10.1073/pnas.1416569111

28. Le GM, Kay AW, Bayless NL, et al. Increased proinflammatory responses of monocytes and plasmacytoid dendritic cells to influenza a virus infection during pregnancy. $J$ Infect Dis. 2016;214 (11):1666-1671. doi:10.1093/infdis/jiw448

29. Dekel N, Gnainsky Y, Granot I, Mor G. Inflammation and Implantation. Am J Reprod Immunol. 2010;63(1):17-21. doi:10.11 11/j.1600-0897.2009.00792.x

30. Aghaeepour N, Ganio EA, Mcilwain D, et al. An immune clock of human pregnancy. Sci Immunol. 2017;2(15):1-12. doi:10.1126/sciimmunol.aan2946

31. Bonne-Année S, Kerepesi L, Hess J, et al. Extracellular traps are associated with human and mouse neutrophil and macrophage mediated killing of larval Strongyloides. Microbes Infect. 2014;16 (6):502-511. doi:10.1016/j.micinf.2014.02.012

32. Meiners J, Reitz M, Rüdiger N, et al. IL-33 facilitates rapid expulsion of the parasitic nematode Strongyloides ratti from the intestine via ILC2- And IL-9-driven mast cell activation. PLoS Pathog. 2020;16 (12):1-20. doi:10.1371/journal.ppat.1009121

33. Trajman A, MacDonald TT, Elia CCS. Intestinal immune cells in Strongyloides stercoralis infection. J Clin Pathol. 1997;50 (12):991-995. doi:10.1136/jcp.50.12.991

34. Schantz-Dunn J, Nour NM. Malaria and pregnancy: a global health perspective. Rev Obstet Gynecol. 2009;2(3):186-192. doi:10.3909/ riog0091

35. Josiane Honkpéhèdji Y, Romeo Adegbite B, Fréjus Zinsou J, et al. Association of low birth weight and polyparasitic infection during pregnancy in Lambaréné, Gabon. Trop Med Int Health. 2021;26 (8):973-981. doi:10.1111/tmi.13591

36. Lau R, Chris RB, Phuong MS, et al. Treatment of soil-transmitted helminth infections in pregnancy: a systematic review and meta-analysis of maternal outcomes. J Travel Med. 2020;27:2. doi:10.1093/jtm/taz079

37. Dreyfuss ML, Msamanga GI, Spiegelman D, et al. Determinants of low birth weight among HIV-infected pregnant women in Tanzania. Am J Clin Nutr. 2001;74(6):814-826. doi:10.1093/ajcn/74.6.814
38. Chiowanich P, Mangklabruks A, Rerkasem A, et al. The risk factors of low birth weight infants in the Northern part of Thailand. $J$ Med Assoc Thai. 2012;95(3):358-365.

39. Yatich NJ, Jolly PE, Funkhouser E, et al. The effect of malaria and intestinal helminth coinfection on birth outcomes in Kumasi, Ghana. Am J Trop Med Hyg. 2010;82(1):28-34. doi:10.4269/ajtmh.2010.09-0165

40. Elliott AM, Ndibazza J, Mpairwe H, et al. Treatment with anthelminthics during pregnancy: what gains and what risks for the mother and child? Parasitology. 2011;138(12):1499-1507. doi:10.1017/ S0031182011001053

41. LaBeaud AD, Nayakwadi Singer M, McKibben M, et al. Parasitism in Children Aged Three Years and Under: relationship between Infection and Growth in Rural Coastal Kenya. PLoS Negl Trop Dis. 2015;9(5):e0003721. doi:10.1371/journal.pntd.0003721

42. Mireku MO, Boivin MJ, Davidson LL, et al. Impact of helminth infection during pregnancy on cognitive and motor functions of one-year-old children. PLoS Negl Trop Dis. 2015;9(3):e0003463. doi:10.1371/journal.pntd.0003463

43. Malézieux-Picard A, Saint-Paul MC, Dellamonica J, et al. Severe intestinal obstruction due to Strongyloides stercoralis in a pregnant woman. Med Mal Infect. 2017;47(6):429-431. doi:10.1016/j.medmal.2017.05.007

44. Toussi AG, Mazinani R, Ariae N. Death of pregnant woman with pemphigus vulgaris disease due to strongyloides stercoralis infection: a case report. Iran J Obstet Gynecol Infertil. 2013;16(80):17-19.

45. Heaton J, Shippey S, Macri C, Macedonia C. Intestinal helminthes infestation in pregnancy: a case report and literature review. Mil Med. 2002;167(11):954-955. doi:10.1093/milmed/167.11.954

46. Wikman-Jorgensen PE, Llenas-Garcia J, Shedrawy J, et al. Costeffectiveness of different strategies for screening and treatment of Strongyloides stercoralis in migrants from endemic countries to the European Union. BMJ Glob Heal. 2020;5(5):1-10. doi:10.1136/ bmjgh-2020-002321

47. King CL. Is ivermectin safe in pregnancy? Lancet Glob Heal. 2020;8 (1):e12-e13. doi:10.1016/S2214-109X(19)30490-5

48. Van Hees S, Raimon S, Fodjo JNS, Colebunders R. Safety of ivermectin during pregnancy. Lancet Glob Heal. 2020;8(3):e338. doi:10.1016/S2214-109X(19)30555-8

49. Merck \& Co. Stromectol (Ivermectin). 2009:1-7.

50. Center for Drug Evaluation and Research. Center for Drug Evaluation and Research Approval Package for Ivermectin. 1996. https://www.accessdata.fda.gov/drugsatfda_docs/nda/96/050742ap. pdf. Accessed September 8, 2021.

51. Overseas Refugee Health Guidance. Immigrant and Refugee Health CDC. Available from: https://www.cdc.gov/immigrantrefugeehealth/ guidelines/overseas-guidelines.html?CDC_AA_refVal=https $\% 3 \mathrm{~A} \% 2 \mathrm{~F} \%$ 2 Fwww.cdc.gov\%2Fimmigrantrefugeehealth $\% 2$ Fguidelines $\%$ 2Foverseas\%2Fintestinal-parasites-overseas.html. Accessed August 8, 2021.

52. Gyorkos TW, St-Denis K. Systematic review of exposure to albendazole or mebendazole during pregnancy and effects on maternal and child outcomes, with particular reference to exposure in the first trimester. Int $J$ Parasitol. 2019;49(7):541-554. doi:10.1016/j. ijpara.2019.02.005

\section{Publish your work in this journal}

Research and Reports in Tropical Medicine is an international, peerreviewed, open access journal publishing original research, case reports, editorials, reviews and commentaries on all areas of tropical medicine, including: Diseases and medicine in tropical regions; Entomology; Epidemiology; Health economics issues; Infectious disease; Laboratory science and new technology in tropical medicine;

Parasitology; Public health medicine/health care policy in tropical regions; and Microbiology. The manuscript management system is completely online and includes a very quick and fair peer-review system. Visit http://www.dovepress.com/testimonials.php to read real quotes from published authors.

Submit your manuscript here: http://www.dovepress.com/research-and-reports-in-tropical-medicine-journal 